\title{
Maturity Onset Diabetes Mellitus: Response to Intensive Dietary Management
}

\author{
D. R. HADDEN \\ D. A. D. MONTGOMERY, \\ E. A. WILSON, K. D. BUCHANAN \\ R. J. SKELLY, \\ E. R. TRIMBLE, J. A. WEAVER,
}

British Medical fournal, 1975, 3, 276-278

to $200 \mathrm{~g}$ /day for a week. Average weight for height and age was obtained from the tables of the Society of Actuaries. ${ }^{1}$

Dietary advice was to restrict food intake in proportion to the

\section{Summary}

Analysis of the first six months of intensive dietary management of 57 maturity onset diabetics showed that a large proportion of such patients could be satisfactorily controlled without the need of either oral hypoglycaemic agents or insulin. A dietitian's assessment of the patient's adherence to the prescribed diet allowed groups of good and poor dieters to be selected. Among the poor dieters the plasma insulin and triglyceride levels were significantly increased though plasma glucose levels were not significantly higher. Dietary adherence may thus be an important prognostic risk factor in this group of diabetic patients.

\section{Introduction}

As part of our investigation into the relation of ischaemic heart disease to diabetes mellitus a prospective study of the treatment of maturity onset diabetic patients was begun in September 1972. All such diabetic patients referred to the outpatient clinic aged 40-70 years with classical symptoms of diabetes mellitus were eligible for inclusion. Those with "borderline" abnormalities of glucose tolerance were excluded. Part of our aim was to assess the effectiveness of intensive dietary management in the diabetic control of this group of patients without the aid of oral hypoglycaemic agents. We report here on the initial results achieved.

\section{The Study}

This long-term study was designed to compare prospectively the effect of a sulphonylurea with that of a biguanide on the lipid metabolism and cardiovascular complications in patients with maturity onset diabetes. To establish a baseline from which the effects of hypoglycaemic treatment could be assessed we decided to make an intensive effort to achieve a uniform pattern of adherence to the prescribed diet. This necessitated additional dietetic supervision and more frequent visits to hospital than is usual for this type of patient. At diagnosis a standard $50-\mathrm{g}$ oral glucose tolerance test (G.T.T.) was performed after a week on a carbohydrate intake of at least $200 \mathrm{~g} /$ day if there was evidence of previous dietary restriction. Patients were reviewed once a month; all attended fasting and the plasma glucose, insulin, gastrointestinal hormones, lipids, and blood fibrinogen levels were measured each time. Patients were seen at each visit by the dietitian and physician. The G.T.T. was repeated at the end of the sixth month after the carbohydrate content of the diet had again been increased

Diabetes Clinic, Royal Victoria Hospital, Belfast BT12 6BA

D. R. HADDEN, M.D., F.R.C.P., Consultant Physician

D. A. D. MONTGOMERY, M.D., F.R.C.P., Consultant Physician

R. J. SKELLY, M.D., F.R.C.P., Consultant Physician

E. R. TRIMBLE, M.D., M.R.C.P., Senior Registrar

J. A. WEAVER, M.D., F.R.C.P., Consultant Physician

E. ANNE WILSON, S.R.D., Senior Metabolic Dietitian

Department of Medicine, The Queen's University of Belfast

K. D. BUCHANAN, M.D., F.R.C.P., Senior Lecturer patient's excess weight, and the intake fell in the calorific range of 3.3-9.6 MJ/day (800-2300 kcal/day) with a mean value of $6.5 \mathrm{MJ}$ $(1540 \mathrm{kcal})$. Carbohydrate was limited to not more than $40 \%$ of the calorific value. A new "food-plan" card was prepared. The dietitian was responsible for the initial instruction and this was followed by a home visit by a community nurse. A special effort was made to ensure that the patient was seen by the dietitian each month. At these interviews the patients were graded on a five-point scale (1-5) according to their adherence to the prescribed diet. This was a subjective rating based on the dietitian's assessment of the degree of co-operation shown by the patient. A rating of 1 was given only when the patient was thought to have been really conscientious, 2 allowed for some errors, and 3,4 , and 5 were progressively worse.

\section{PATIENTS}

There were 156 potential study patients ( 100 men, 56 women); 98 have been enrolled for further follow-up: of these 85 were still attending at the time of writing. One died, two moved away, and seven did not keep recent appointments. One was removed from the study owing to an error in interpretation of the trial rules and two had progressive deterioration of their diabetic symptoms during the initial six-month period of diet, and treatment with insulin was started. Of the 58 potential study patients who were rejected from this consecutive series ( 37 men, 21 women) 21 , though new diabetics and new to the clinic, had already been established on some form of treatment (diet or oral hypoglycaemics) by the referring doctor; 10 had sufficiently severe diabetes to require urgent insulin treatment; and 15 had a concomitant general illness or were on steroid treatment. Twelve patients were excluded for various reasons-they were too frail to attend, in a mental hospital, etc. (Even by basically simple criteria of selection about $40 \%$ of the presenting patients were excluded.)

\section{METHODS}

Plasma insulin was measured by radioimmunoassay and cholesterol and triglyceride by standard methods. During the first year whole blood glucose was measured by the AutoAnalyzer A.A.I method. Later we used another method which measured plasma glucose (AutoAnalyzer A.A.II). As there is uncertainty about the real correction factors necessary to convert whole blood glucose to plasma glucose,$^{23}$ and about the difference in clinical practice between the reducing substances measured by these techniques and the "true glucose" concentration determined enzymatically we applied an arbitrary correction factor of $+13 \%$ to the whole blood glucose readings to allow them to be analysed and the results to be presented as plasma glucose.

\section{Results}

Over the six-month period, taking the mean of the five numerical grades, 37 patients were graded by the dietitian less than 2 and had lost over $100 \%$ of their excess weight; 10 had a mean grade of 3 or over and had lost only $35 \%$ of their excess weight. Ten were graded 2 to 3 .

Fig. 1 shows the mean weight of 57 patients who have completed the initial six-month follow-up. Their mean weight loss was about $8.2 \mathrm{~kg}(18 \mathrm{lb})$ and weight loss proceeded steadily over the period. The slight rise at the sixth month was related to the routine one-week period of $200 \mathrm{~g}$ carbohydrate intake before the second G.T.T. There was some difference in weight loss between men and women. The 
mean weight at onset among the 41 men was $83.5 \mathrm{~kg}$ (184 lb; expected average weight for height and age $72.1 \mathrm{~kg}(159 \mathrm{lb})$ ) and they lost after six months an average of $9.1 \mathrm{~kg}(20 \mathrm{lb})$, which was $92 \%$ of their excess weight for those overweight at onset. The mean weight at onset of the 16 women was $71.7 \mathrm{~kg}$ (158 lb; expected average weight $61.7 \mathrm{~kg}(136 \mathrm{lb}))$ and they lost $5.4 \mathrm{~kg}(12 \mathrm{lb})$ within the six months $(64 \%)$. There was no overall difference in the dietitian's assessment of dietary adherence between men and women: 29 men and 10 women had a mean rating of less than 2 ; eight men and two women had a rating of $2-2 \cdot 9$; and six men and four women had a rating of over 3 .

In the whole group fasting plasma glucose levels fell considerably, especially during the first month: this was in contrast to the rather steady fall in mean weight throughout the first six months. At the sixth month 42 of the 57 patients had a fasting venous plasma glucose below $8.0 \mathrm{mmol} / \mathrm{l}(1 \mathrm{k} \mathrm{mg} / 100 \mathrm{ml})$. Mean fasting plasma insulin for the whole group showed no definite trend in spite of the fall in glucose and the loss in weight. None of the patients had any residual symptoms from their original diagnosis of diabetes.

Mean fasting cholesterol and triglyceride levels showed little change. There was a definite fall in mean triglyceride after the first month but not thereafter, again suggesting that initial hypertriglyceridaemia was chiefly carbohydrate-induced. Plasma gastrin and glucagon levels in this series have been reported elsewhere. ${ }^{4}$ Plasma fibrinogen levels showed no significant trend during the first six months of diet but we will continue to monitor them as a possible risk factor for cardiovascular events.

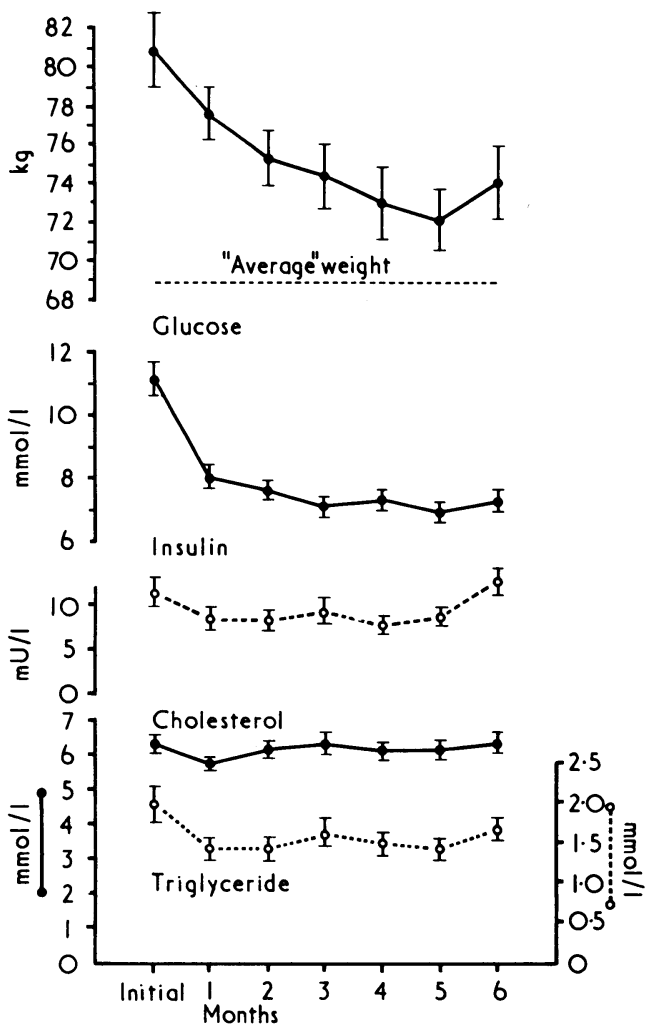

FIG. 1-Mean values (+S.E. of mean) each month for weight and fasting levels of glucose, insulin, cholesterol, and triglyceride in 57 patients during first six months of intensive dietary management.

Conversion: SI to Traditional Units-Glucose: $1 \mathrm{mmol} / 1 \approx 18 \mathrm{mg} / 100 \mathrm{ml}$. Cholesterol: $1 \mathrm{mmol} / 1 \approx 38.6 \mathrm{mg} / 100 \mathrm{ml}$. Triglyceride: $1 \mathrm{mmol} / 1 \approx 88.5 \mathrm{mg}$ | $100 \mathrm{ml}$.

The mean weight, glucose, insulin, and triglyceride values all rose at the sixth month after one week on the $200-\mathrm{g}$ carbohydrate intake. This indicated that the mean level of dietary adherence was well below this intake and even a relatively mild increase in food intake in this type of diabetic patient produced a significant change in metabolic patterns. Subsequent trends in this study show that the improved profile at five months was generally attained by return to carbohydrate restriction subsequent to the second G.T.T. but the final outcome on this aspect is not yet clear.

The mean values after the 50-g G.T.T. (fig. 2) show the relatively

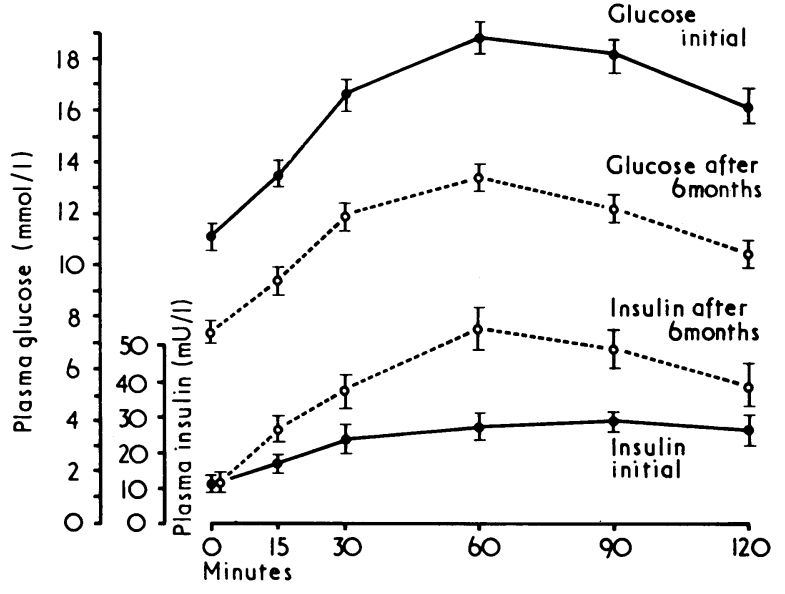

FIG. 2-Mean values ( \pm S.E. of mean) for $50-\mathrm{g}$ oral glucose tolerance test at diagnosis and after six months' intensive dietary management in 57 patients.

high plasma glucose levels at diagnosis, which was in keeping with the symptomatic nature of the diabetes. After six months these levels fell, but the mean results were still abnormal on any usually accepted criteria. ${ }^{5}$ At the sixth month 36 out of the 57 patients had a two-hour plasma glucose of less than $10.0 \mathrm{mmol} / 1(180 \mathrm{mg} / 100 \mathrm{ml})$. Plasma insulin levels were rather low and responded poorly to the glucose load at onset, but showed great improvement after six months.

There were no significant differences in plasma glucose values between those patients graded by the dietitian (mean grading of the first six monthly assessments) as showing good $(<2)$, fair $(2-2 \cdot 9)$, or poor $(<3)$ adherence, either fasting or at two hours (see table). There were more definite differences in mean plasma insulin in the same three groups, the highest values being in those who were not keeping to their diet over the six-month period. A similar pattern was found for fasting cholesterol and triglyceride, poor dieting being associated with hypertriglyceridaemia.

Mean Glucose, Insulin, and Lipid Measurements ( \pm S.E. of Mean) at Diagnosis and after Six Months' Dietary Management according to Dietitians' Grade (Mean of First Six Monthly Reviews)

\begin{tabular}{|c|c|c|c|c|c|}
\hline \multicolumn{3}{|c|}{ Dietitians' Mean Grade: } & \multirow{2}{*}{$\frac{\begin{array}{c}\text { Good } \\
(<2)\end{array}}{37}$} & \multirow{2}{*}{$\begin{array}{c}\begin{array}{c}\text { Fair } \\
(2-2 \cdot 9)\end{array} \\
10\end{array}$} & \multirow{2}{*}{$\begin{array}{c}\frac{\text { Poor/Bad }}{(\geqslant 3)} \\
10\end{array}$} \\
\hline No. of patie & nts. & . & & & \\
\hline \multicolumn{6}{|c|}{ Plasma Glucose (mmol/l) } \\
\hline $\begin{array}{l}\text { Fasting } \\
\text { Two-hour }\end{array}$ & $\left\{\begin{array}{l}\text { Initial ... } \\
\text { Six-month } \\
\text { Initial ... } \\
\text { Six-month }\end{array}\right.$ & $\begin{array}{l}\cdots \\
\cdots \\
\cdots\end{array}$ & $\begin{array}{r}11 \cdot 2 \pm 0.55 \\
9 \cdot 0 \pm 0.61 \\
16 \cdot 4 \pm 0.83 \\
10 \cdot 3 \pm 0.72\end{array}$ & $\begin{array}{c}11 \cdot 6 \pm 1 \cdot 2 \\
7 \cdot 0 \pm 0 \cdot 67 \\
17 \cdot 2 \pm 1 \cdot 7 \\
11 \cdot 3 \pm 1 \cdot 9\end{array}$ & $\begin{array}{c}11.2 \pm 1 \cdot 6 \\
7.9 \pm 0.89 \\
15.7 \pm 1.9 \\
11.6 \pm 1.7\end{array}$ \\
\hline \multicolumn{6}{|c|}{ Plasma Insulin ( $m U / L)$} \\
\hline $\begin{array}{l}\text { Fasting } \\
\text { Two-hour }\end{array}$ & $\left\{\begin{array}{l}\text { Initial ... } \\
\text { Six-month } \\
\text { Initial ... } \\
\text { Six-month }\end{array}\right.$ & $\begin{array}{l}\cdots \\
\cdots \\
\cdots\end{array}$ & $\begin{array}{r}11 \pm 1 \\
9 \pm 1 \\
26 \pm 4 \\
28 \pm 4\end{array}$ & $\begin{array}{l}10 \pm 1 \\
12 \pm 2 \\
21 \pm 6 \\
40 \pm 11\end{array}$ & $\begin{array}{l}12 \pm 2 \\
22 \pm 5 \\
28 \pm 6 \\
52 \pm 12\end{array}$ \\
\hline \multicolumn{6}{|c|}{ Blood Cholesterol (mmol/l) } \\
\hline & $\begin{array}{l}\text { Initial ... } \\
\text { Six-month }\end{array}$ & $\begin{array}{l}. \\
\cdots\end{array}$ & $\begin{array}{l}6.5 \pm 0.23 \\
6.6 \pm 0.23\end{array}$ & $\begin{array}{l}6 \cdot 1 \pm 0.54 \\
5 \cdot 8 \pm 0.49\end{array}$ & $\begin{array}{l}7 \cdot 2 \pm 0.47 \\
6.6 \pm 0.52\end{array}$ \\
\hline \multicolumn{6}{|c|}{ Blood Triglyceride (mmol/l) } \\
\hline & $\begin{array}{l}\text { Initial ... } \\
\text { Six-month }\end{array}$ & $\therefore$ & $\begin{array}{l}2.3 \pm 0.35 \\
1.6 \pm 0.12\end{array}$ & $\begin{array}{l}2 \cdot 1 \pm 0.23 \\
1.5 \pm 0.23\end{array}$ & $\begin{array}{l}3.2 \pm 0.79 \\
2.4 \pm 0.51\end{array}$ \\
\hline
\end{tabular}

Converszon: SI to Traditional Units

Glucose: $1 \mathrm{mmol} / 1 \approx 18 \mathrm{mg} / 100 \mathrm{ml}$.

Triglyceride: $1 \mathrm{mmol} / 1 \approx 88.5 \mathrm{mg} / 100 \mathrm{ml}$.

\section{Discussion}

After the University Group Diabetes Programme trial ${ }^{6}$ and our own corroborative retrospective and prospective data $^{78}$ the association between ischaemic heart disease and treatment of maturity onset diabetes by oral hypoglycaemic agents has been the subject of several projected long-term epidemiological studies and randomized therapeutic trials. Initial reports will not appear for five or more years, though other retrospective 
clinical studies of acute myocardial infarction have shown an association between mortality or the incidence of ventricular fibrillation and the use of oral hypoglycaemic agents. ${ }^{9}$ We have been impressed by the acceptability to the patient of the relatively intensive dietary management adopted in our study, and if present trends continue a much smaller proportion of our maturity onset diabetic patients will be considered for treatment with oral hypoglycaemic agents. After the six-month assessment only six of our patients were admitted to the second stage of this study and started on an oral hypoglycaemic agent. We do not intend here to analyse this group in detail, but the criterion for advising oral hypoglycaemic treatment was a fasting plasma glucose consistently above $11 \mathrm{mmol} / 1(200 \mathrm{mg} /$ $100 \mathrm{ml}$ ).

Fasting plasma glucose, which is a relatively unimportant factor in predicting risk of a subsequent cardiovascular event, ${ }^{10}$ showed as good an improvement in the good dieters as in those who co-operated less well. Thus, if plasma glucose alone was used as an index of diabetic control all of these patients might be classified as making a satisfactory response. The significant hyperinsulinaemia and hypertriglyceridaemia in the poor dieters shows that factors other than fasting glucose must be considered in assessing diabetic control in a long-term study. In this initial report these factors have not been affected by any therapeutic regimen other than diet and one foresees the complicated effects of random allocation on the basis of plasma glucose alone of some of these patients to treatment groups with one or other type of oral hypoglycaemic treatment or insulin. Furthermore, the simple fact of real carbohydrate intake as a prime cause of hypertriglyceridaemia in this subgroup of diabetic patients may not always have been rigidly assessed in studies of lipoprotein levels in patients attending a routine diabetic clinic. ${ }^{11} 12$

Another aspect of our study is the demonstration that the fall in fasting blood glucose which occurs in the first month of dietary treatment is much greater than in any subsequent month, though weight loss proceeds steadily throughout the first six months (except where interrupted by the $200-\mathrm{g}$ carbohydrate intake before the second G.T.T., which itself indicates the overall degree of dietary restriction attained for the rest of the time). This is in keeping with the concept that carbohydrate restriction rather than weight loss is the determining factor in the control of the diabetic state. ${ }^{13}$

Dr. E. Trimble was in receipt of a Royal Victoria Hospital Fellowship. The plasma insulin assays were supported by a grant from the British Diabetic Association.

\author{
References \\ 1 Society of Actuaries, Build and Blood Pressure Study, vol. I, p. 16. \\ Chicago, Society of Actuaries, 1959. \\ 2 Morrison, B., and Fleck, A., Clinica Chimica Acta, 1973, 45, 293. \\ ${ }^{3}$ Holtkamp, H. C., Verhoef, N. J., and Leijnse, B., Clinica Chimica Acta, \\ 1975, 59, 41 . \\ 4 Trimble, E. R., et al., European Association for the Study of Diabetes, \\ Annual Meeting, 1974 \\ ${ }^{5}$ Montgomery, D. A. D., and Welbourn, R. B., Medical and Surgical \\ Endocrinology, p. 406. London, Arnold, 1975. \\ ${ }^{6}$ University Group Diabetes Program, Diabetes, 1970, 19, Suppl. 2, 747 \\ and 789. \\ ${ }^{7}$ Hadden, D. R., Montgomery, D. A. D., and Weaver, J. A., Lancet, 1972, \\ $1,335$. \\ ${ }^{8}$ Boyle, D., et al., Lancet, 1972, 1, 338. \\ ${ }^{9}$ Soler, N. G., et al., Lancet, 1974, 1, 475. \\ ${ }^{10}$ Hadden, D. R., et al., Practitioner, 1973, 210, 655. \\ 11 Hayes, T. M., Clinical Endocrinology, 1972, 1, 247. \\ 12 Nikkila, E. A., and Kekki, M., Metabolism, 1973, 22, 1. \\ ${ }^{13}$ Wall, J. R., Pyke, D. A., and Oakley, W. G., British Medical fournal, \\ $1973,1,577$
}

\title{
Evidence of Gentamicin Nephrotoxicity in Patients with Renal Allografts
}

\author{
J. M. WELLWOOD， P. M. SIMPSON， J. R. TIGHE，A. E. THOMPSON
}

British Medical fournal, 1975, 3, 278-281

\section{Summary}

Renal damage was assessed by measuring urinary enzyme excretion in 180 patients with renal allografts. Thirty-six of these patients were studied during 53 courses of treatment with antimicrobial agents which had begun when renal function was stable. Gentamicin was the only antimicrobial agent which was associated with an increase in urinary enzyme activity. There was

\section{St. Thomas's Hospital, London S.E.1}

J. M. WELLWOOD, M.A., F.R.C.s., Honorary Senior Registrar, Transplantation Unit (Present address: St. Bartholomew's Hospital, London E.C.1)

J. R. TIGHE, M.D., F.R.C.P., Professor of Histopathology

A. E. THOMPSON, M.S., F.R.c.s., Consultant Surgeon and Director of Transplantation Unit

Department of Statistics, Queen Mary College, University of London, London

P. M. SIMPSON, B.A., Senior Research Assistant usually also evidence of reduced renal function. Renal morphological changes similar to those produced by gentamicin in rats were observed in human allograft biopsy specimens obtained during gentamicin treatment.

\section{Introduction}

The activity of certain urinary $\beta$-glycosidases is a sensitive indicator of renal cell damage. Increased urinary activity of $N$-acetyl $\beta$-D-glucosaminidase (NAG) and $\beta$-galactosidase (GAL) have been found in patients with renal disease. ${ }^{1-3}$ Some workers have noted an increase in urinary NAG activity during rejection of renal allografts. ${ }^{4}{ }^{5}$ Increased urinary activity of these enzymes indicates renal injury but not the cause of injury. During a 15-month study of 180 patients with renal allografts the administration of gentamicin was always followed by a rise in urinary enzyme activity within three days of the start of treatment. The effect of gentamicin on the excretion of urinary enzymes and renal morphology in rats was therefore studied. At doses of $5 \mathrm{mg} \mathrm{Kg}^{-1}$ day${ }^{-1}$ increased excretion of urinary enzymes and renal morphological changes were found. ${ }^{6}$ Kosek et al. ${ }^{7}$ noted renal morphological changes in rats given doses as low as $1 \mathrm{mg} \mathrm{kg}^{-1}$ day $^{-1}$. We describe here the effects of gentamicin treatment on patients with renal allografts. 